\title{
Power Quality Improvement Using VLLMS Based Adaptive Shunt Active Filter
}

\author{
Pravat Kumar Ray
}

\begin{abstract}
The power quality problem in the power system is increased with the use of non-linear devices. Due to the use of non-linear devices like power electronic converters, there is an increase in harmonic content in the source current. Due to this there is an increase in the losses, instability and poor voltage waveform. To mitigate the harmonics and provide the reactive power compensation, we use filters. There are different filters used in the power system. Passive filters provide limited compensation, so active filters can be used for variable compensation. In this paper, a shunt active filter has been made adaptive using a Variable Leaky Least Mean Square (VLLMS) based controller. Proposed adaptive controller can be able to compensate for harmonic currents, power factor and nonlinear load unbalance. DC capacitor voltage has been regulated at a desired level using a PI controller and a self-charging circuit technique. The design concept of proposed adaptive controller for shunt active filter has been verified through simulation and experimentation.
\end{abstract}

Index Terms-APF, harmonics, neural network, power quality, Variable Leaky Least Mean Square (VLLMS).

\section{INTRODUCTION}

$\mathrm{O}$ VER the past few years, rapid increase in the use of nonlinear loads causes many power quality issues, like high current harmonics, low power factor and excessive neutral current. The increased harmonics, reactive power and unbalance cause increase in voltage distortion, line losses and instability when harmonic current travel upstream and produce drop across the line impedance, which leads distortion in power system. Usually, passive filters are used for suppression of harmonics but their applications are limited to fixed amount of compensation. Passive filters are also not capable in providing solutions in presence of unbalance and variable reactive power compensation. Another disadvantage with passive filter is the problem of resonance which amplifies current of certain harmonic frequencies. The solution to above mentioned problem can be realized using a shunt active power filter [1]-[4].

APF performance basically depends on the way of estimating the reference compensating signal. Instantaneous reactive power (IRP) theory [5], synchronous reference frame (SRF) theory [6] and modified p-q theory [7] etc. are the well-known methods of generating current reference by maintaining dc link voltage. These above cited methods are very attractive for their

Manuscript received January 26, 2018. (Corresponding Author: Pravat Kumar Ray.)

The author is with the Department of Electrical Engineering, National Institute of Technology, Rourkela 769008, India (e-mail: rayp@nitrkl.ac.in).

Digital Object Identifier 10.24295/CPSSTPEA.2018.00015 simplicity and ease of implementation but they are incapable in providing appropriate solution in presence of more harmonics, reactive power and unbalance or their combinations with limited power rating of voltage source inverter (VSI) used as APF. Soft computing techniques such as neural network have been discussed in [8]-[10]. So it can be seen that use of artificial intelligence has been used very often as a controller in shunt active filter. A model reference adaptive sliding mode control (MRASMC) using radial basis function (RBF) [11] has been used as a controller in single phase active power filter (APF). An adaptive sliding mode control with a double loop recurrent neural network (DLRNN) [12] structure has been used for nonlinear dynamics system. A new control using sliding mode control -2 [13] has also been implemented in Hybrid Series Active Power Filter (HSAPF) for making it robust and stable.

So far as signal processing techniques are concerned, Least Mean Square (LMS) is a favorable choice. Because of fixed step size in conventional LMS technique, it has slower rate of convergence. This can be overcome using time varying step size [14]. Since least mean square of error is taken as the cost function in LMS algorithm, weights are not bounded and it takes more time to respond because of stalling effect [14]. To overcome this, leaky LMS algorithm is employed where magnitudes of weights are also included in cost function to nullify the stalling and parameter drifting effect [15], [16].

This paper proposes a VLLMS based technique for shunt active filter. Harmonic currents and reactive component of nonlinear load can be extracted using a circuit based on above technique. Both harmonic and reactive current of nonlinear load together with signal from self-charging circuit [17] form the reference injection current of adaptive hysteresis controller for generating switching signal of three phase IGIT voltage source inverter. It becomes also able to compensate for unbalanced load currents and bring the power factor of the supply side to become unity. DC capacitance is also maintained at a desired level using a self-charging circuit. The main contribution of the paper is on the implementation of VLLMS in active power filter circuit for faster adaptation of active filter to any variations in operating conditions. Conventional weight updating algorithm is modified by replacing with VLLMS based weight updating algorithm, which greatly enhances the speed of algorithm and extraction. Another contribution of this paper is the use of Adaptive Hysteresis Band Current Control technique for avoiding acoustic noise uneven switching frequency in hysteresis band current control.

The paper is organized as follows. Section II discusses in detail about adaptive shunt active power filter. Section III shows the simulation results and discussion. Section IV experimentally 
verifies the proposed algorithm. Section V concludes the paper.

\section{Adaptive Shunt Active Power Filter}

\section{A. System Configuration}

The current source $i_{L}$ is used to model the instantaneous current of the nonlinear load that can be represented by

$$
\begin{gathered}
i_{L}(t)=i_{L 1} \sin \left(\omega t+\phi_{L 1}\right)+\sum_{n=2}^{\infty} i_{L n} \sin \left(n \omega t+\phi_{L n}\right) \\
i_{L}=i_{L 1} \sin \omega t \cos \phi_{L 1}+i_{L 1} \sin \phi_{L 1} \cos \omega t+\sum_{n=2}^{\infty} i_{L n} \sin \left(\omega t+\phi_{L n}\right) \\
i_{L}=i_{L 1, p}+i_{L 1, q}+i_{L n}
\end{gathered}
$$

Where $i_{L 1}$ is the peak value of the fundamental component and $i_{L n}$ is the peak value of the harmonic component. $\phi_{L 1}$ and $\phi_{L n}$ are the phase angles of the fundamental and the harmonic components. Fig. 1 shows the circuit for shunt APF. Voltage source $v$ represents the instantaneous supply voltage at the PCC with $i_{s}$ as its instantaneous supply current. The injection current of the shunt active filter is denoted by $i_{i n j}$. The first order low-pass filter in series with the VSI output is represented by inductor $L_{s h}$ with resistor $R_{s h}$ as the inverter losses. $V_{d c} / 2$ denotes the voltage of each capacitor unit.

In (1) above, the instantaneous current of the nonlinear load is expanded into 3 terms. The first term is the load instantaneous fundamental phase current $i_{L 1, p}$ which is always in phase with the supply voltage. The second term $i_{L 1, p}$ is the load instantaneous fundamental quadrature current which is always $90^{\circ}$ out of phase with the supply voltage. The third term $i_{L n}$ is the load instantaneous harmonic currents. From Fig. 1, it can be shown that

$$
i_{s}+i_{i n j}=i_{L 1, p}+i_{L 1, q}+i_{L n}
$$

In order to have $i_{s}$ that is almost in phase with $v$ and at the same time consists only of the fundamental component, from (2)

$$
i_{i n j}=i_{L 1, q}+i_{L n}
$$

The dc voltage of each capacitor $V_{d c} / 2$ is also measured and passed to the self-charging circuit to regulate to its reference voltage level $V_{d c}^{*} / 2$. The output signal from the self-charging circuit $i_{d c}$ together with $i_{L 1, q}$ and $i_{L n}$ will form the reference injection current of the adaptive shunt active filter $i_{i n j}^{*}$.

\section{B. Adaptive VLLMS based Fundamental Active Component Extraction}

Here a VLLMS algorithm is used for extraction of fundamental active component of current from load current. For that, signal can be modelled as

$$
y(t)=\sum_{n=1}^{N} A_{n} \sin \left(n \omega t+\phi_{n}\right)
$$

$y(k)=\sum_{n=1}^{N}\left[A_{n} \sin (n \omega k T) \cos \phi_{n}+A_{n} \cos (n \omega k T) \sin \phi_{n}\right]$

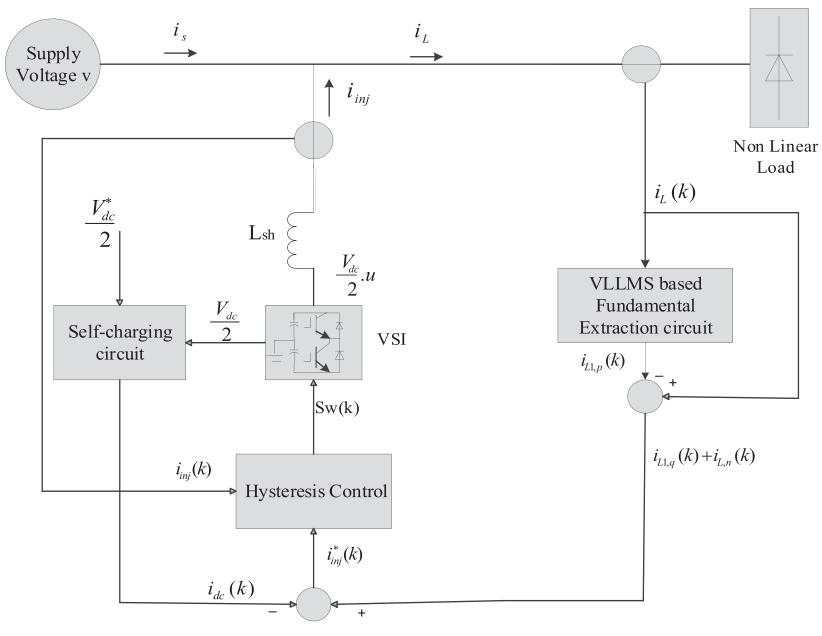

Fig. 1. System block diagram of single-phase adaptive shunt active filter.

(4) can be rewritten in parametric form as follows

$$
y(k)=H(k) X
$$

$H(k)=\left[\begin{array}{llll}\sin (\omega k T) \cos (\omega k T) & \ldots \sin (n \omega k T) & \cos (n \omega k T)\end{array}\right]$

The vector of unknown parameter

$X=\left[\begin{array}{lllll}A_{1} \cos \left(\phi_{1}\right) & A_{1} \sin \left(\phi_{1}\right) & \ldots & A_{n} \cos \left(\phi_{n}\right) & A_{n} \sin \left(\phi_{n}\right)\end{array}\right]^{T}$

The VLLMS algorithm is applied to estimate the state. The algorithm minimizes the square of the error recursively by altering the unknown parameter $X_{k}$ at each sampling instant using (8) given below

$$
\begin{gathered}
\hat{X}_{k+1}=\left(1-2 \mu_{k} \gamma_{k}\right) \hat{X}_{k}+2 \mu_{k} e_{k} \hat{y}_{k} \\
\hat{y}_{k}=H(k) \hat{X}_{k}
\end{gathered}
$$

where the error signal is

$$
e_{k}=y_{k}-\hat{y_{k}}
$$

Step size $\mu_{k}$ is varied for better convergence of the VLLMS algorithm in the presence of noise.

$$
\mu_{k+1}=\lambda \mu_{k}+\gamma_{k} R_{k}^{2}
$$

where $R_{k}$ represents the autocorrelation of $e_{k}$ and $e_{k-1}$. It is computed as

$$
R_{k}=\beta R_{k-1}+(1-\beta) e_{k} e_{k-1}
$$

where $\beta$ is an exponential weighting parameter and $0<\beta<1$, and $\lambda(0<\lambda<1)$ and $\gamma>0$ control the convergence time.

The variable leakage factor $\gamma_{k}$ can be adjusted as

$$
\gamma_{k+1}=\gamma_{k}-2 \mu_{k} \rho e_{k} \hat{y_{k}} X_{k-1}
$$


After the updating of the vector of unknown parameter using VLLMS algorithm,

$$
i_{L 1, p}=X_{1} H_{11}
$$

As seen from Fig. 1, the current output of the VLLMS based fundamental extraction circuit is subtracted from the load current. The subtracted output serves as a major component in reference current generation. Fig. 2 shows the flow chart of the active component of fundamental current extraction scheme using VLLMS algorithm.

\section{DC Capacitor Self Charging Circuit}

To regulate the dc capacitor voltage at the desired level, an additional real power has to be drawn by the adaptive shunt active filter from the supply side to charge the two capacitors. The energy $E$ stored in each capacitor can be represented as

$$
E=\frac{1}{2} C\left(\frac{V_{d c}}{2}\right)^{2}
$$

If the value of the dc capacitor voltage changes from $V_{d c}$ to $V_{d c}^{\prime}$ the change in energy is represented by

$$
\Delta E=\frac{1}{2} C\left[\left(\frac{V_{d c}^{\prime}}{2}\right)^{2}-\left(\frac{V_{d c}}{2}\right)^{2}\right]
$$

The charging energy delivered by the three-phase supply side to the inverter for each capacitor will be

$$
\begin{aligned}
E_{a c} & =3 P t \\
& =3\left(V_{r m s} I_{d c r m s} \cos \phi\right) t
\end{aligned}
$$

$P$ : additional real power required

$t$ : charging time

$V_{r m s}$ : value of instantaneous supply voltage $v$

$I_{d c-r m s}$ : value of the instantaneous charging current $i_{\mathrm{dc}}$

$\phi$ : phase difference between supply voltage and charging current

$$
E_{a c}=3 \frac{V}{\sqrt{2}} \frac{I_{d c}}{\sqrt{2}} \frac{T}{2}=\frac{3 V I_{d c} T}{4}
$$

Neglecting the switching losses in the inverter and according to the energy conservation law, the following equation holds from (15) and (16).

$$
\begin{gathered}
\Delta E=E_{a c} \\
\frac{1}{2} C\left[\left(\frac{V_{d c}^{\prime}}{2}\right)^{2}-\left(\frac{V_{d c}}{2}\right)^{2}\right]=\frac{3 V I_{d c} T}{4} \\
I_{d c}=\frac{2 C\left[\left(\frac{V_{d c}^{\prime}}{2}\right)^{2}-\left(\frac{V_{d c}}{2}\right)^{2}\right]}{3 V T}
\end{gathered}
$$

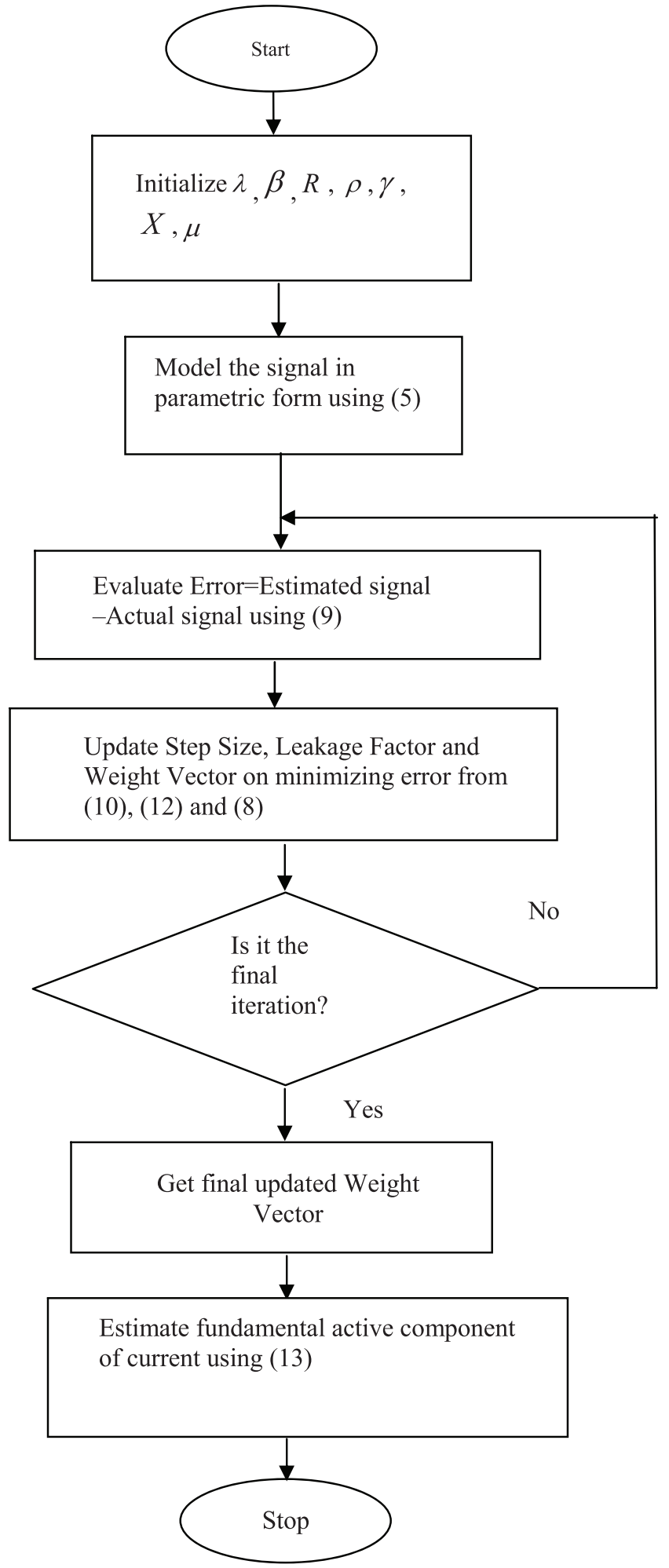

Fig. 2. Flow chart of the active fundamental current extraction scheme of VLLMS algorithm.

To maintain the value of each dc capacitor voltage at the reference level $V_{d c}^{*} / 2, V_{d c} / 2$ is measured and fed back to a PI controller as shown in Fig. 3 to manipulate $V_{d c}^{\prime} / 2$. So that it can be used in (17) to compute the required peak value of the charging current $I_{d c}$ from the supply side. The PI controller also helps in reducing 


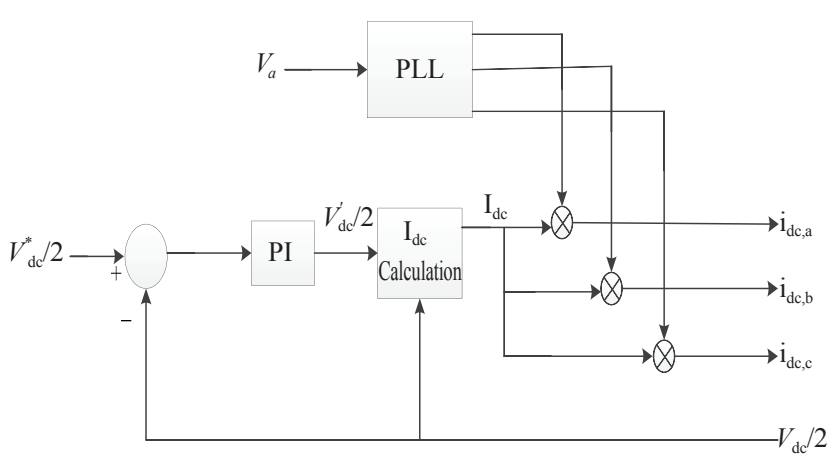

Fig. 3. Three phase self-charging circuit with PI controller.

the steady state offset between the reference $V_{d c}^{*} / 2$ and the actual $V_{d c} / 2$. The PLL synchronizes itself with the supply voltage of phase a i.e $v_{a}$ and gives three output sinewaves which are $120^{\circ}$ out of phase with each other. These sine waves are multiplied with $I_{d c}$ to obtain three phase $i_{d c}$. In order to force the supply side to deliver $i_{d c}$, a term consisting of this $i_{d c}$ is added to the three phase injection currents $i_{i n j}$ that can be represented by

$$
\begin{aligned}
& i_{i n j, a}=i_{L 1, q a}+i_{L n, a}-I_{d c} \sin \omega t \\
& i_{i n j, b}=i_{L 1, q b}+i_{L n, b}-I_{d c} \sin \left(\omega t-120^{\circ}\right) \\
& i_{i n j, c}=i_{L 1, q c}+i_{L n, c}-I_{d c} \sin \left(\omega t+120^{\circ}\right)
\end{aligned}
$$

Fig. 3 shows the schematic of three phase self-charging circuit with PI controller. The negative sign indicates the flow of charging current into the VSI. For each phase it lags by an angle of $120^{\circ}$. The reference currents calculated shows that the adaptive shunt APF injects $i_{L n}$ and $i_{L 1, q}$ into the line to compensate the harmonic currents and the reactive power respectively, and at the same time it receives the charging current $i_{d c}$ from the supply to regulate the dc capacitor voltage.

An inductor which acts a low pass filter is connected in between the filter and the PCC to eliminate the higher order harmonics. The compensating signals along with the original injecting currents are given to a adaptive hysteresis current controller to generate the switching pulses for the IGBTs or switches in the inverter to produce the required currents.

\section{Adaptive Hysteresis Current Controller}

Adaptive hysteresis control has been used in this paper to actualize (18) at the output of VSI. The mathematical expression derived in (18) has been used as the reference signal $i_{i n j}^{*}$ for the adaptive hysteresis control. The injected current $i_{i n j}$ at the output of VSI is measured and fed back to the adaptive hysteresis control as it's another input. The adaptive hysteresis control will take the difference between $i_{i n j}^{*}$ and $i_{i n j}$ as given by

$$
\Delta i_{i n j}=i_{i n j}^{*}-i_{i n j}
$$

Taking into account the value of $\Delta i_{i n j}$, the adaptive hysteresis control will switch the IGBT of VSI as per the expression given in (20).

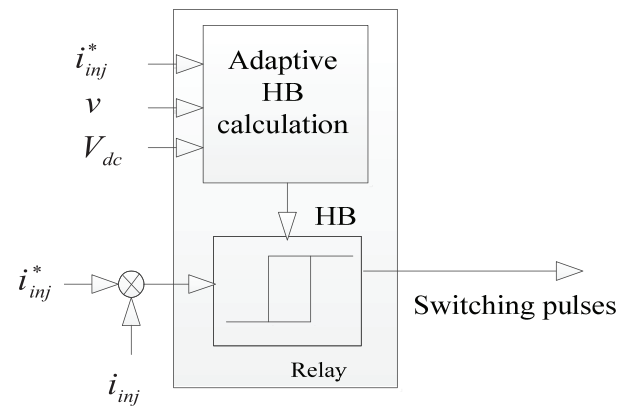

Fig. 4. Adaptive hysteresis band current controller.

$$
S w=\text { adaptive hys }\left(\Delta i_{i n j}\right)=\left\{\begin{array}{c}
1 \text { if } \Delta i_{i n j}>H B \\
0 \text { if } \Delta i_{i n j}<-H B
\end{array}\right.
$$

Where $H B$ is the hysteresis band and $S w$ is the status of the IGBT, "1" represents on and "0" represents off. The value of " $u$ " shown in Fig. 1 will be "1" if $S w=" 1 "$ and "-1" if $S w=" 0 "$.

In hysteresis band current control, it has a fixed hysteresis band due to which the switching frequency is not constant, are uneven in nature. Due to this uneven switching frequency acoustic noise is produced. To overcome these drawbacks, an Adaptive Hysteresis Band Current Control technique has been used which adaptively changes the hysteresis band according to system parameters such as reference source current, source voltage, switching frequency and dc capacitor voltage, so that the switching frequency is maintained almost constant. The hysteresis band [18] can be calculated according to the following equation.

$$
H B=\frac{0.125 V_{d c}}{f_{c} L}\left[1-\frac{4 L^{2}}{V_{d c}^{2}}\left(\frac{v}{L}+m\right)^{2}\right]
$$

Where, $f_{c}$ is modulation frequency, $m=\frac{d i_{i n j}^{*}}{d t}$ is the slope of the command current wave and $v$ is the supply voltage.

In adaptive hysteresis band current controller, since modulation frequency $f_{c}$, almost remains constant, this improves the PWM performances and APF substantially. Calculated hysteresis band using above (21), is applied to hysteresis band current controller as shown in Fig. 4 for switching pulse generation to be fed back to inverter.

\section{SimiUlation StUdies}

Various simulations at different power system conditions have been carried out with the proposed VLLMS based controller. Simulations have been done using power system block set under MATLAB/Simulink environment.

\section{A. Simulation Results With Three Phase Nonlinear Load}

The performance of the system with non-linear load has been analysed by simulating the shunt APF filtering using both the 
TABLE I

System PARAmeters

\begin{tabular}{cc}
\hline \hline System Parameter & Value \\
\hline Voltage & $220 \mathrm{~V}$ \\
Frequency & $50 \mathrm{~Hz}$ \\
$\mathrm{~L}_{\mathrm{s}}$ & $3.5 \mathrm{mH}$ \\
$\mathrm{R}_{\mathrm{s}}$ & 0.01 \\
$\mathrm{R}_{\text {load }}$ & $10 \mathrm{ohms}$ \\
$\mathrm{L}_{\text {load }}$ & $10 \mathrm{mH}$ \\
$\mathrm{R}_{\mathrm{f}}$ & $1 \mathrm{ohm}$ \\
$\mathrm{L}_{\mathrm{f}}$ & $0.3 \mathrm{mH}$ \\
\hline \hline
\end{tabular}

control strategies. The system data on which the simulation has been carried out is shown in the TABLE I.

The MATLAB /Simulink results are presented in Fig. 5. Fig. 5(a) shows the source current of phase-a without any compensation. The THD of this current as shown in Fig. 5(b) is 17.93\%, which exceeds the IEEE standards. The source current of phase-a after compensation using proposed controller is shown in Fig. 5(c). The harmonics are reduced and the source current is almost sinusoidal. The THD of the source current has been reduced to very low value which is permissible $(2.84 \%)$ and the harmonic analysis of the current is shown in Fig. 5(d).

The voltage of the DC side capacitor is maintained constant using a self-charging circuit in the VLLMS based current decomposer. The voltage of the single capacitor on the DC side is shown in the Fig. 6.

\section{B. Simulation Results With Combination of Non-Linear Load and Unbalanced Linear Load}

For another performance comparison simulation for combination of non-linear load and unbalanced linear load has been carried out. The phase-a source current before compensation is shown in the Fig. 7(a) and the harmonic analysis is shown in the Fig. 7(b). The THD of source current before compensation for the combination of loads is $14.23 \%$.

The simulation is done using proposed VLLMS based controller and phase a source current after compensation is shown in Fig. 7(c) and the harmonic analysis of the phase a current is shown in the Fig. 7(d). DC Side capacitor voltage is shown in Fig. 7(e).

\section{Simulation Results With Unbalanced Linear Load}

To analyze the system performance, another condition has been taken into consideration. Linear load with unbalanced nature is connected to the source. The unbalanced load current is shown here in Fig. 8(a), whereas after compensation with the proposed technique it becomes more sinusoidal as shown in Fig. 8(b). Spectral analysis of load current is found to be $20.93 \%$ from Fig. 8(c) and with the proposed method, the THD has been reduced to $2.21 \%$ clearly shown in Fig. 8(d). Simulation parameter for this condition has been presented in TABLE II.

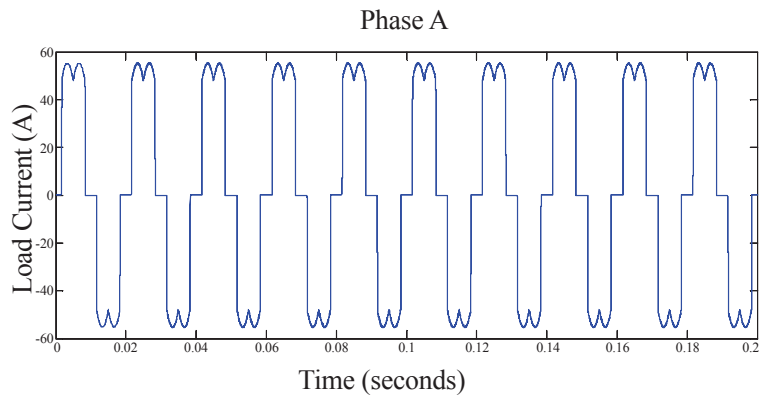

(a)

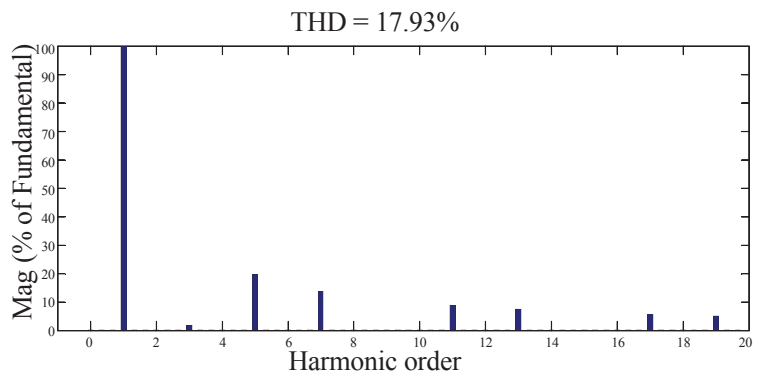

(b)

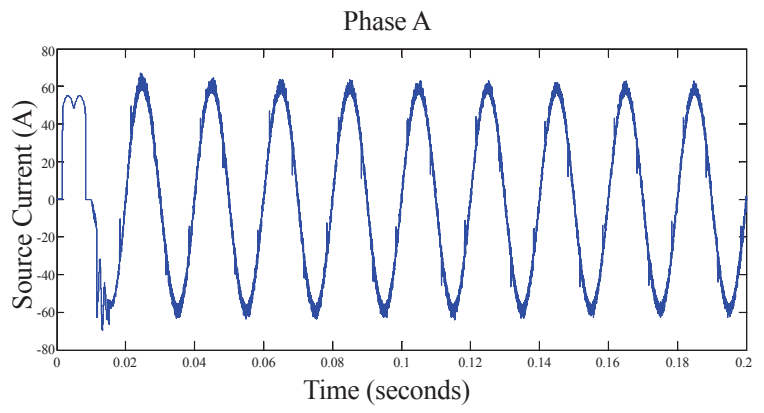

(c)

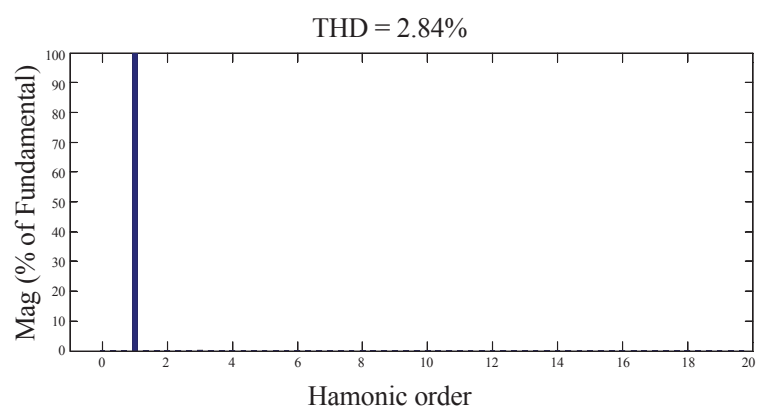

(d)

Fig. 5. (a) Phase-a source current before compensation, (b) Harmonic analysis of phase-a source current before compensation, (c) Phase-a source current after compensation using proposed controller, (d) Harmonic analysis of phase-a source current after compensation.

\section{Simulation Results With Balanced Highly Inductive Load}

This condition is very much essential to test the effectiveness of the proposed method. In this condition balanced and highly inductive loads are connected to the source. Parameters considered for this simulation are shown in TABLE III. Inductive load current 




Fig. 6. Voltage of DC side capacitor in VLLMS based decomposer.

TABLE II

Filter and Load Parameters for Unbalanced Case

\begin{tabular}{cc}
\hline \hline Parameter & Value \\
\hline Unbalanced load resistance $\left(\mathrm{R}_{\text {labc }}\right)$ & $10 \mathrm{ohms}, 20 \mathrm{ohms}, 30 \mathrm{ohms}$ \\
Unbalanced load inductance $\left(\mathrm{L}_{\text {labc }}\right)$ & $0.2 \mathrm{H}, 0.5 \mathrm{H}, 0.65 \mathrm{H}$ \\
$\mathrm{R}_{\mathrm{f}}$ & $1 \mathrm{ohm}$ \\
$\mathrm{L}_{\mathrm{f}}$ & $0.3 \mathrm{mH}$ \\
\hline \hline
\end{tabular}

TABLE III

Filter and Load Parameters for Highly Inductive LoAd

\begin{tabular}{cc}
\hline \hline Parameter & Value \\
\hline Load resistance $\left(\mathrm{R}_{\text {labc }}\right)$ & 20 ohms, $20 \mathrm{ohms}, 20 \mathrm{ohms}$ \\
Load inductance $\left(\mathrm{L}_{\text {labc }}\right)$ & $10 \mathrm{H}, 10 \mathrm{H}, 10 \mathrm{H}$ \\
$\mathrm{R}_{\mathrm{f}}$ & $1 \mathrm{ohm}$ \\
$\mathrm{L}_{\mathrm{f}}$ & $0.3 \mathrm{mH}$ \\
\hline \hline
\end{tabular}

obtained from the simulation has been shown in Fig. 9(a), after compensation with the application of VLLMS decomposer control algorithm the source current become sinusoidal as shown in Fig. 9(b). From the spectrum analysis the harmonic content can be known, THD of the load current is $30.50 \%$ as per Fig. 9(c) which has been reduced to 2.61\% for VLLMS decomposer control algorithm as shown in Fig. 9(d).

\section{EXPERIMENTAL RESULTS AND Discussion}

The real validation of the proposed scheme has been verified by hardware experiment performed in the laboratory. DS1103 controller board has been used which is compatible with MATLAB to control the experimental setup, the controller has been developed in MATLAB/dSPACE interactive platform. The PWM signal generated from the control board are passed through the driver circuit which is fed to the inverter. The experimental setup developed in the laboratory includes voltage and current sensor boards, driver circuit, inverters. The hardware setup block diagram is shown in Fig. 10. Single phase shunt active power filter is connected in to the distributed system at the load end. The experiment is conducted in the following steps, first the source is feeding the load without the power conditioner connected to the system and the nonlinear load current is sensed which is highly rich in harmonics.

The shunt APF with the proposed control scheme has been

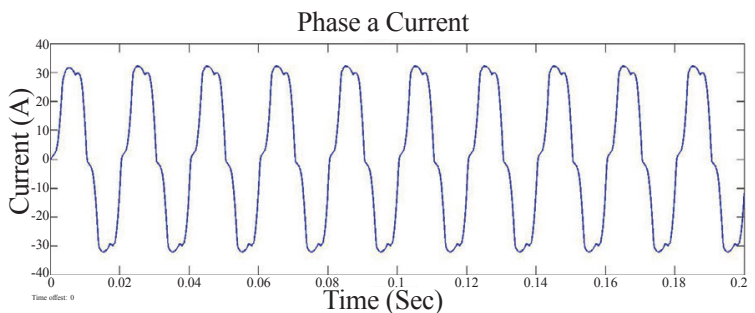

(a)

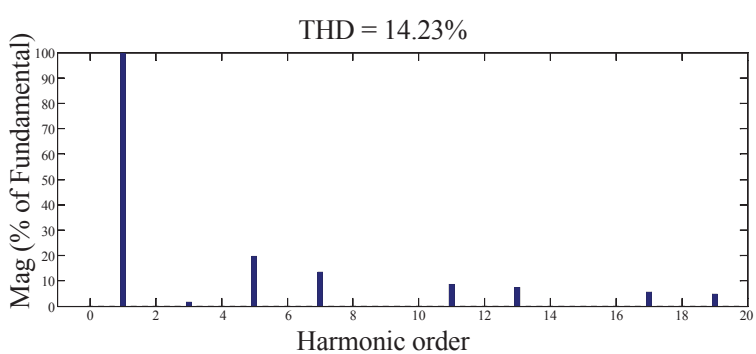

(b)

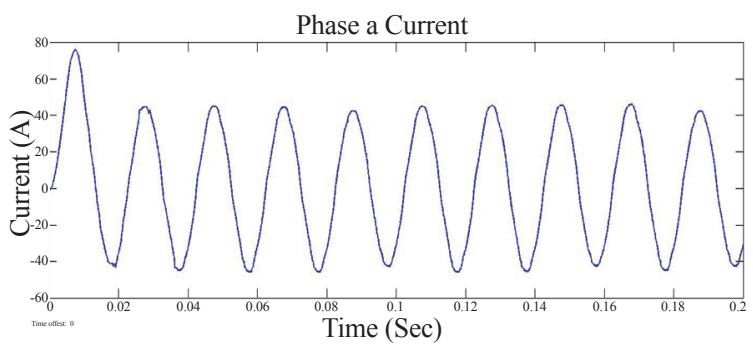

(c)

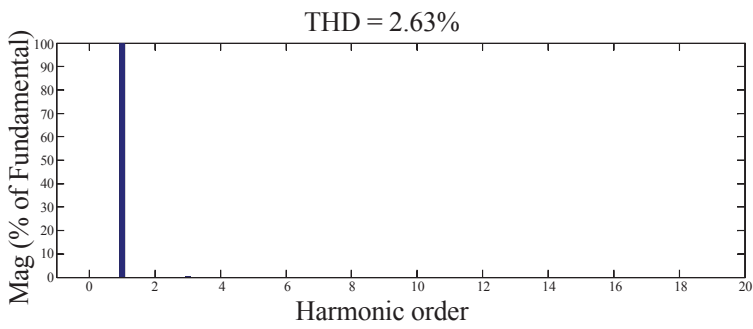

(d)

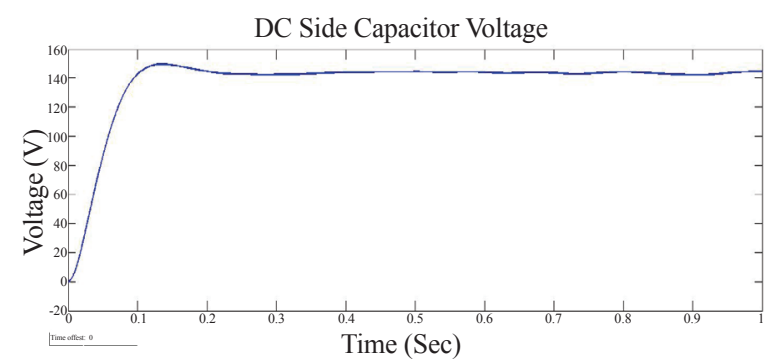

(e)

Fig. 7. (a) Phase-a source current before compensation for combination of load, (b) Harmonic analysis of the phase-a source current before compensation for combination of load, (c) Phase-a source current after compensation for combination of load using VLLMS based controller, (d) Harmonic analysis of phase-a source current after compensation for combination of load using VLLMS based controller, (e) DC side capacitor voltage after combination of load using VLLMS decomposer.

designed and implemented. Various cases have been considered 


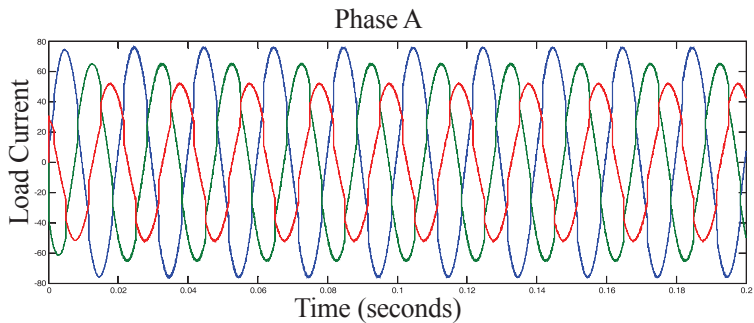

(a)

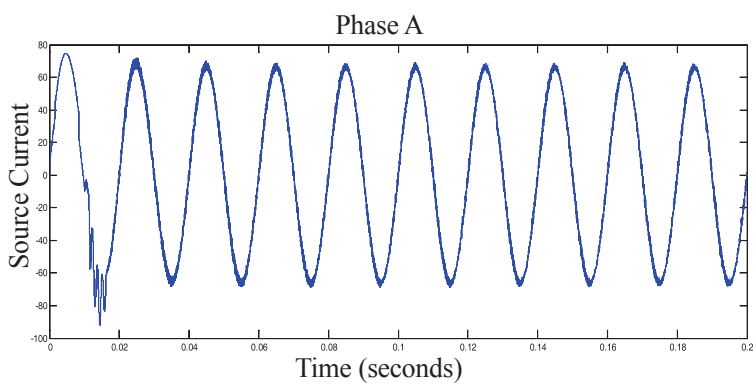

(b)

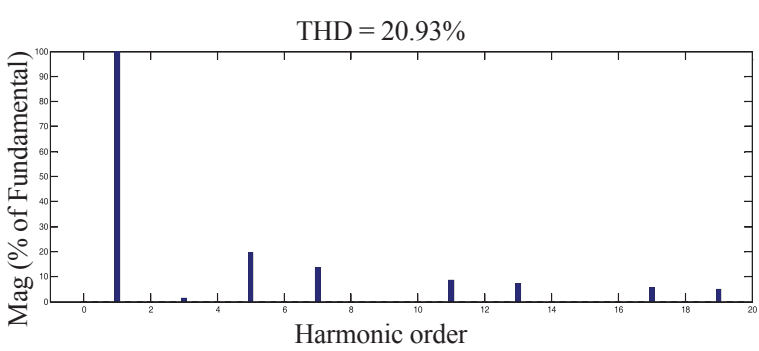

(c)

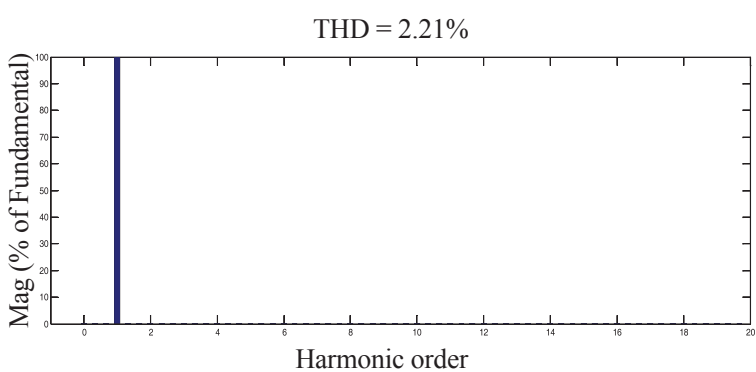

(d)

Fig. 8. (a)Unbalanced load current, (b) Phase-a source current after compensation after combination of load using VLLMS decomposer, (c) Harmonic analysis for load current, (d) Analysis for source current with VLLMS decomposer.

for the validation of the simulation work. The experimental parameters are listed in the TABLE IV.

\section{A. Performance of Shunt APF based on VLLMS with Nonlinear Load}

The three phase source is connected to the nonlinear load, which injects harmonics to the distribution system. The harmonic rich load current is measured and presented in Fig. 11(a). The VLLMS algorithm is applied for the compensation of load harmonics. The source current after compensation is presented in Fig. 11(b).



(a)

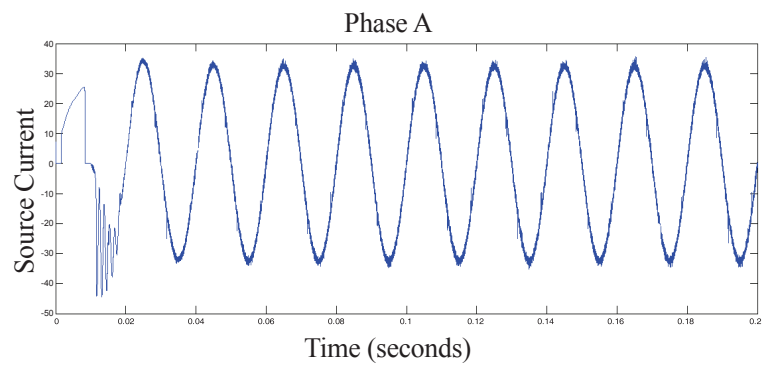

(b)

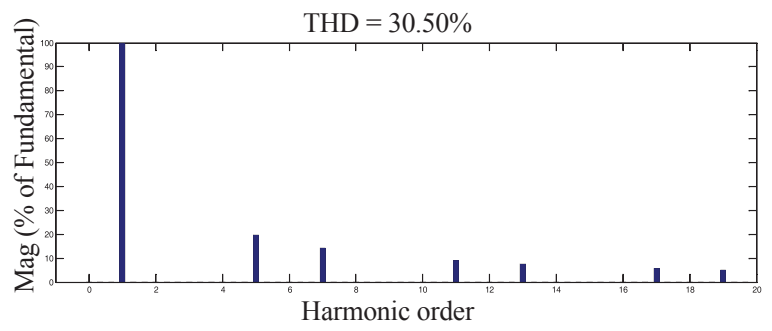

(c)

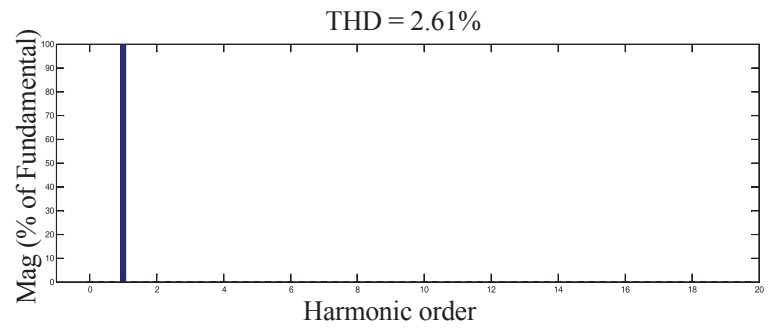

(d)

Fig. 9. (a) Balanced load current, (b) Phase-a source current after compensation after combination of load using VLLMS decomposer, (c) Harmonic analysis for load current, (d) Harmonic analysis for source current with VLLMS decomposer.

The THDs before and after compensation have been given in Fig. 11(c) and Fig. 11(d) respectively.

\section{B. Performance of Shunt APF Based on VLLMS Under Nonlin- ear Load and Unbalance Linear Load}

The source is feeding a combination of linear and nonlinear load, where the linear load considered is unbalanced in this case. The measured load current is presented in Fig. 12(a) with nonlinear load and unbalance linear load. The shunt APF with VLLMS is employed for compensation, where the source current is compensated as shown in Fig. 12(b). 


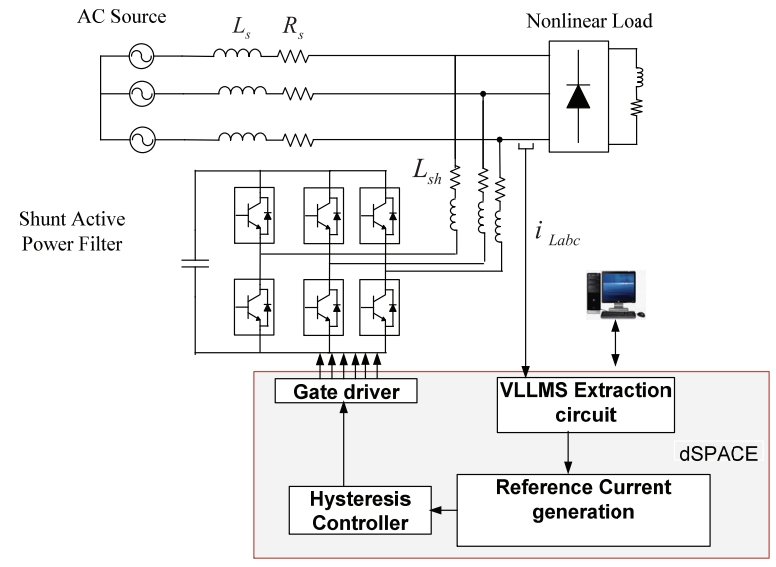

Fig. 10. Block diagram of experimental prototype compensation.

TABLE IV

System Parameter for Experimental Setup

\begin{tabular}{cc}
\hline \hline System Voltage & $110 \mathrm{~V}$ \\
\hline Frequency & $50 \mathrm{~Hz}$ \\
\hline Non linear load & $30 \Omega, 50 \mathrm{mH}$ \\
\hline Unbalance Load & $30 \Omega, 50 \mathrm{mH}$ \\
& $20 \Omega, 40 \mathrm{mH}$ \\
& $25 \Omega, 30 \mathrm{mH}$ \\
\hline Coupling inductance source & $0.2 \Omega, 0.05 \mathrm{mH}$ \\
\hline Interfacing inductance shunt APF & $0.02 \Omega, 0.003 \mathrm{mH}$ \\
\hline DC link capacitor & $2100 \mu \mathrm{F}$ \\
\hline \hline Switching frequency & $10 \mathrm{kHz}$ \\
\hline
\end{tabular}

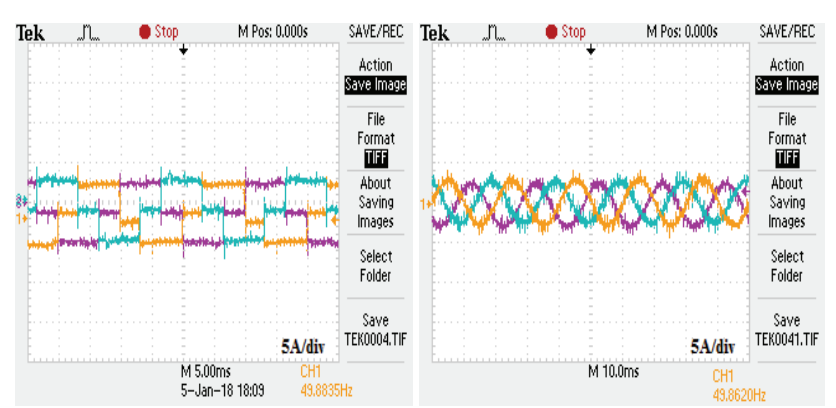

(a)

(b)

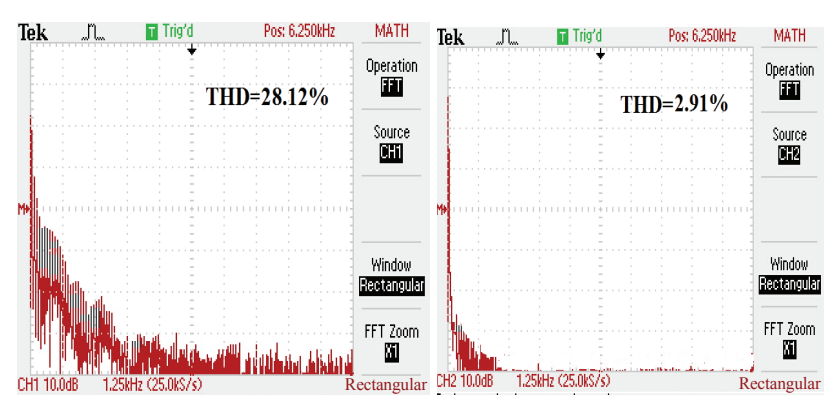

(c)

(d)

Fig.11. Nonlinear load case (a) Load current, (b) Source current after compensation, (c) THD before compensation of load current, (d) THD after compensation source current.

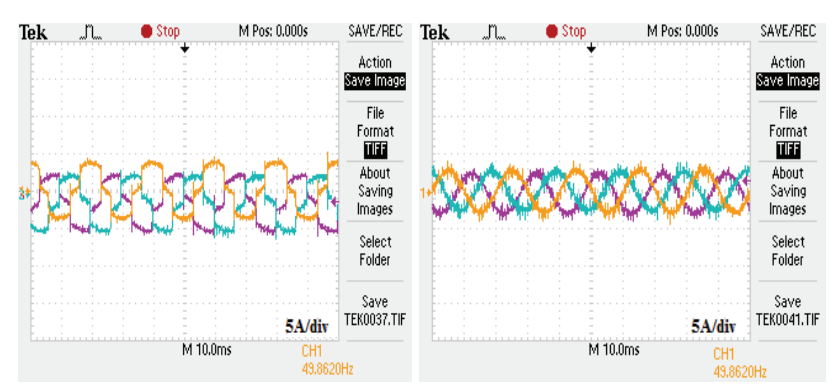

(a)

(b)

Fig.12. Nonlinear load and unbalance linear load case (a) Load current, (b) Source current after compensation.

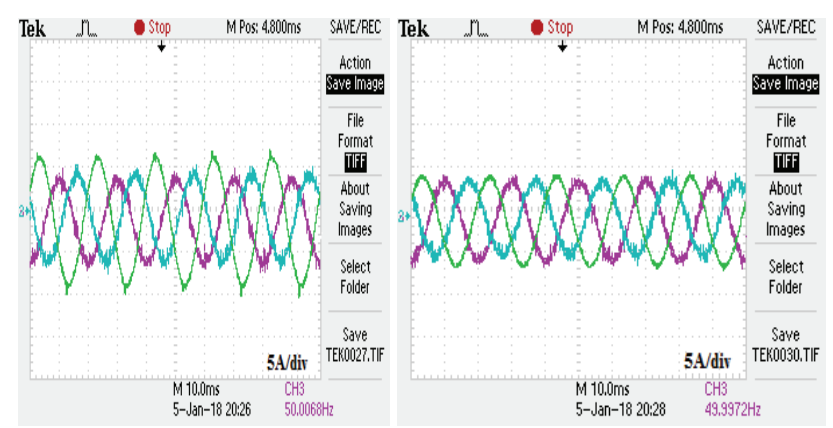

(a)

(b)

Fig.13. Unbalance linear load case (a) Load current, (b) Source current after compensation.

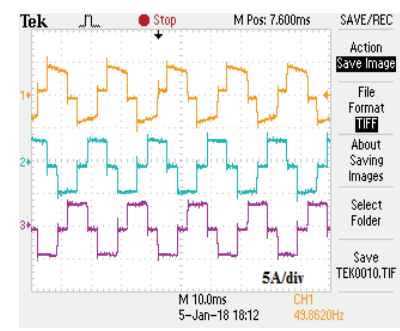

(a)

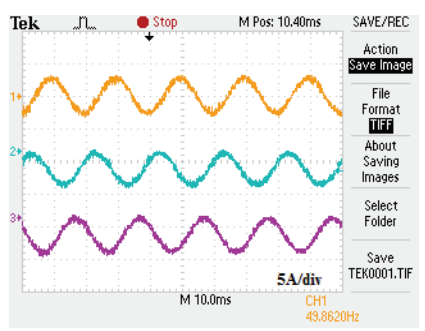

(b)
Fig.14. Highly inductive load case (a) Load current, (b) Source current after compensation.

\section{Performance of Shunt APF Based on VLLMS Under Unbalance Linear Load}

In this case, an unbalanced linear load has been connected to the main grid. The sensed load current is shown in Fig. 13(a). After compensation by Shunt APF with VLLMS, the compensated source current is shown in Fig. 13(b).

\section{Performance of Shunt APF Based on VLLMS Under Highly Inductive Load Case}

A highly inductive nonlinear load has been connected to the main grid where the load current is sensed and presented in Fig. 14(a). The highly inductive load current is rich in harmonics which need to be eliminated. The shunt APF with the proposed method is employed for the compensation of the harmonics and to 
maintain the source current as sinusoidal. The source current after compensation is presented in Fig. 14(b).

\section{Conclusions}

In this paper, a new control design for the shunt active power filter has been presented. The controller design is based on VLLMS based algorithm for fundamental current extraction. With the use of this proposed algorithm, the performance of shunt active filter has been enhanced. The proposed shunt active power filter compensates balanced and unbalanced nonlinear load currents. Self-charging capability has also been integrated into the proposed shunt active power filter for regulating the dc capacitor voltage. Simulation and experimental results under various system operating conditions have verified the effectiveness and robustness of the proposed adaptive shunt active filter.

\section{REFERENCES}

[1] M. I. M. Montero, E. R. Cadaval, and F. B. González, "Comparison of control strategies for shunt active power filters in three-phase fourwire systems," IEEE Transactions on Power Electronics, vol. 22, no.1, pp. 229-236, Jan. 2007.

[2] B. Singh, K. Al-Haddad, and A. Chandra, "A review of active filter for power quality improvement," IEEE Trans. on Ind. Electron., vol. 46, no. 5, pp. 960-971, Oct. 1999.

[3] P. Jintakosonwit, H. Akagi, H. Fujita, and S. Ogasawara, "Implementation and performance of automatic gain adjustment in a shunt active filter for harmonic damping throughout a power distribution system," IEEE Trans. Power Electron., vol. 17, no. 3, pp. 438-447, May 2002.

[4] D. Gao and X. Sun, "A new method to generate current reference for active power filter," in Proc. IEEE CIEP, Alcapulco, Mexico, 2000, pp. 99-103.

[5] H. Akagi, Y. Kanazawa, and A. Nabae, "Instantaneous reactive power compensators comprising switching devices without energy storage components," IEEE Transactions on Industry Applications, vol. 20, no. 3, pp. 625-630, May/June 1984.

[6] S. D. Swain and P. K. Ray, "Harmonic current and voltage compensation using HSAPF based on hybrid control approach for synchronous reference frame method," International Journal of Electrical Power \& Energy Systems, vol. 75, pp. 83-90, 2016.

[7] M. Rezkallah, A. Chandra, B. Singh, and R. Niwas, "Modified PQ control for power quality improvement of standalone hybrid wind diesel battery system," in Proc. IEEE Power India Conference, New Delhi, 19-22 Dec. 2012.

[8] B. Singh, P. Jayaprakash, S. Kumar, and D. P. Kothari, "Implementation of neural network controlled three leg VSC and a transformer as three phase four wire DSTATCOM", IEEE Transactions on Industrial Applications, vol. 47, no.4, pp. 1892-1901, July/Aug 2011.
[9] N. Pecharanin, "An application of neural network to harmonic detection in active filter," in Proc. WCCI-ICNN, 1994, vol. 6, pp. 3756-3756.

[10] B. Singh, V. Verma, and J. Solanki, "Neural network based selective compensation of current quality problems in distribution system," IEEE Transactions on Industrial Electronics, vol. 54, no.1, pp. 53-60, Feb 2007.

[11] Y. Fang, J. Fei, and K. Mab, "Model reference adaptive sliding mode control using RBF neural network for active power filter," International Journal of Electrical Power and Energy Systems, vol. 73, pp. 249-258, 2015.

[12] J. Fei and C. Lu, "Adaptive sliding mode control of dynamic systems using double loop recurrent neural network structure," IEEE Transactions on Neural Network and Learning Systems, vol. 29, no. 4, pp. 1275-1286, 2017.

[13] S. D. Swain, P. K. Ray and K. B. Mohanty "Improvement of power quality using a robust hybrid series active power filter," IEEE Transactions on Power Electronics, vol. 32, no. 4, pp. 3490-3498, 2017.

[14] A. K. Pradhan, A. Routray, and Abir Basak, "Power system frequency estimation using least mean square technique," IEEE Trans. Power Del., vol. 20, no. 3, pp.1812-1816, 2005.

[15] B. Subudhi, P. K. Ray, and S. Ghosh, "Variable leaky LMS algorithm based power system frequency estimation," IET Science, Measurement \& Technology, vol. 6, no. 4, pp. 288-297, 2012.

[16] P. K. Ray, P. S. Puhan, and G. Panda, "Real time harmonics estimation of distorted power system signal," International Journal of Electrical Power and Energy System, vol. 75, pp. 91-98, 2016.

[17] L. H. Tey, P. L. So, and Y. C. Chu, "Improvement of power quality using adaptive shunt active filter," IEEE Transactions on Power Delivery, vol. 20, no. 2, pp. 1558-1568, 2005.

[18] M. Kale and E. Ozdemir, "An adaptive hysteresis band current controller for shunt active power filter," Electric Power System Research, vol. 73, pp. 113-119, 2005.

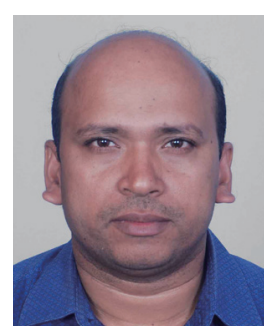

Pravat Kumar Ray received the B.E. degree in Electrical Engineering from Indira Gandhi Institute of Technology Sarang, Odisha, India, in 2000, the M.E. degree in Electrical Engineering from Indian Institute of Engineering Science and Technology, Shibpur, Howrah, India, in 2003, and the Ph.D. degree in Electrical Engineering from National Institute of Technology (NIT) Rourkela, Rourkela, India, in 2011. He was also a Postdoctoral Fellow at Nanyang Technological University, Singapore during Jan. 2016 to June 2017. He is currently an Associate Professor with the Department of Electrical Engineering, NIT Rourkela. He is having more than fifteen years of experience in teaching and research. He has guided 4 $\mathrm{Ph} . \mathrm{D}$ theses and another 5 are yet to get their Ph.D. Degree. His research interests include system identification, signal processing and soft computing applications to power system, power quality, solar irradiance forecasting using sky images and grid integration of renewable energy systems. 